Population Biology of Infectious Diseases, eds. R.M. Anderson and R.M. May, pp. 53-64. Dahlem Konferenzen 1982. Berlin, Heidelberg, New York: Springer-Verlag.

\title{
The Impact of Infectious Disease on Human Demography Today
}

\author{
M. S. Pereira \\ Central Public Health Laboratory \\ Colindale, London NW9 5HT, England
}

\begin{abstract}
In the developing world the present pattern of infectious disease and its effect on morbidity and mortality are similar to the pattern which existed a hundred and fifty years ago in the now developed world. Despite the high infant mortality rate and short life span for adults, population growth continues steadily. In the developed world population growth has been contained in parallel with improvements in living standards and the control of infectious disease.
\end{abstract}

\section{INTRODUCTION}

In the past the effect of infectious disease on population numbers and social structure has certainly been profound as recorded for those parts of the world where information is available.

However, in the developed world at the present time, it would be difficult to demonstrate that infectious disease plays any part in modifying the death rate. The impact of improved public health measures and the understanding of the etiology of infectious diseases and their consequent control by vaccines or other means have brought about a transformation in the infant survival rate and the general life expectancy of whole populations. 
In the developing world a comparable control has not taken place, and infectious disease is even now a major cause of death. From the figures which are available, the scale matches that of England and wales a hundred and fifty years ago.

An examination of the causes of death in the past history of a developed country, such as England, may illuminate what occurs at the present time in many of the poor developing nations.

\section{IMPORTANT INFECTIOUS DISEASES IN THE PAST}

Despite the difficulty of identifying specific diseases in the early accounts of epidemics, some are clearly recognizable. Examples are those with characteristic skin lesions such as plague and smallpox, both of which were important causes of death. In England in the thirteenth century there had been a steady increase in population, but this was suddenly changed to a dramatic fall as a result of the arrival of plague in the so-called Black Death of 1348-49. Various estimates have been made of the size of this decrease. Trevelyan (6) suggested a third or even a half of the population died; Shrewsbury (4), however, thought this an exaggeration and considered it more likely that no more than one twentieth had died. In all events, the scarcity of manpower following this epidemic was an important factor in bringing about an irreversible change in the feudal structure of the country.

Plague never swept the country again in quite the same way, but it was a continual threat for the next three centuries until a final epidemic in 1665-66.

An analysis of deaths in the fifteenth century by means of the examination of testamentary wills by Gottfried (2) showed that only $75 \%$ of the will-making families survived for three generations, and the proportion of testators without surviving sons was $50 \%$. 
The diseases associated with those deaths, called "pestilence," "pox," or "flux," were likely to have been a mixture of plague, smallpox, typhus, influenza, typhoid, and cholera. Malaria and tuberculosis were also important causes of death.

Despite these heavy losses, the population of a town - like London - increased, the toll from disease being continuously reversed by the inflow of immigrants from rural areas and from other countries of Europe. With the end of plague, the whole population of England and Wales rose steadily due to an increased birth rate and a falling death rate, resulting from improvements in the conditions of life, particularly in the abundance of food and the advances of medicine.

Smallpox became the most dreaded disease and led to the death of about one thirteenth of each generation.

Reports abound in the literature of epidemics and their associated mortality, imprecise both as to the type of illness and the numbers affected. It was only in 1837, as a result of the efforts of William Farr (1), that figures for deaths from infectious diseases began to be collected nationally, and since that time it became possible to follow the rise and fall of epidemics and measure, with some accuracy, their effects on the total population. The seasonal incidence, age distribution, and geographical areas of several infectious diseases were defined, and public health measures to control them became a possibility. The nineteenth centruy saw, in fact, a massive increase in population from 15 million in 1839 to 41 million in 1939, and a fall in the infant mortality from between 100-200 per thousand live births to 50 per thousand in 1939. The rate in England and Wales in 1980 is 12 per thousand live births with a population of 50 million.

\section{INFECTIOUS DISEASES IN THE DEVELOPED WORLD TODAY}

At present in the developed world, the old well recognized diseases, as mentioned above, have completely disappeared, with 
the single exception of influenza. This disease remains the one which has proved most unresponsive to control because of the ability of the influenza virus to modify its antigenic structure, which allows it to overcome antibodies already present in the population from previous exposure. In this way epidemics can continue year after year. The age groups most severely affected by influenza are the very young and the aged, and this disease is the only one still causing a significant number of deaths above the normal mean.

Infectious diseases of many varieties, however, remain widespread. Some, such as poliomyelitis, measles, diphtheria, and whooping cough, are largely controlled by the use of vaccines, and streptococcal infections such as scarlet fever became rare with the use of antibiotics.

But besides these there are the constant minor respiratory and gastrointestinal infections which continue completely uncontrolled. The number of viral agents now known to cause such infections has increased steadily in the past 30 years, and it is clear that a whole host of different agents besides influenza $A$ and $B$ causes acute respiratory tract disease. There are five parainfluenza viruses (including mumps), 35 or more serotypes of adenoviruses, coronaviruses, respiratory syncytial virus, and perhaps a hundred different serotypes of rhinoviruses. Causing gastrointestinal infections, besides the bacterial agents, there are many viruses now known to be involved, such as rotaviruses, astroviruses, caliciviruses, and enteric adenoviruses.

These viruses are responsible for a continuous morbidity but a decreasing mortality in the developed world. In 1979 the proportion of deaths which could be attributed to infectious disease was under one half percent of the total number of deaths notified. The most frequent of these infectious diseases were unspecified acute respiratory illnesses, over $20 \%$ of which occurred in infants under one year of age. Almost certainly 
these same viruses contributed in earlier centuries to the vast number of deaths which occurred beyond those that could be attributed to a known infectious disease.

The populations of countries in the developed world are mostly stable, with only modest increases or even in some, such as Germany, with slight decreases in the total numbers. The average natural increase in population per thousand in Europe is 4, compared with 29 in Africa.

\section{INFECTIOUS DISEASES IN THE DEVELOPING WORLD TODAY}

The impact of infectious diseases in the developing world in the past is largely undocumented - and even now in some countries it is difficult to obtain accurate information on the causes of morbidity and mortality. Some of the diseases which were once serious problems in the now developed world are still found endemic or epidemic in certain areas of the developing world. Knowledge of the transmission of plague has now restricted this disease to a few small foci and smallpox has been completely eradicated, but outbreaks of cholera still occur and tuberculosis is still a common disease in much of the Third World. Malaria, which recently seemed to be coming under control, has had a resurgence in Southeast Asia, posing intractable difficulties with insecticide-resistant mosquito vectors and drug-resistant plasmodial parasites.

Besides these diseases there are several which are confined to tropical parts of the world. Schistosomiasis, leishmaniasis, filariasis, trypanosomiasis, and leprosy continue to be important diseases, even though much is known about the causes of these conditions. Their etiological agents together with their intermediate hosts or vectors have been defined, and ways to eradicate or control them are possible. However, these diseases, such as malaria, are not only not coming under control, many are spreading even more widely.

Besides these specifically tropical diseases, all the diseases of the temperate climates are found in these areas as well. 
Poliomyelitis, now a rare disease where vaccination programs have been implemented, still kills or cripples large numbers of children each year in the developing world. Measles in unvaccinated populations may have a case fatality rate of $10 \%$.

The information on infectious diseases which is offered to WHO by some countries in the developing world is unstandardized and reflects the categories of illness which are notifiable in each. In Africa, for example, Algeria places measles at the top of their list, whereas Benin, with even more measles, reports an incidence of malaria seven times greater. Central Africa has even more malaria than Benin but has diarrheal diseases only just below in second place.

TABLE 1 - Main causes of morbidity from infectious diseases notified in countries in the developing world (7).

\begin{tabular}{|c|c|c|c|c|}
\hline Latin America & $\underline{\text { Respiratory }}^{*}$ & Gastro- & Measles & Malaria \\
\hline Argentina & 1 & 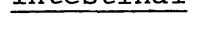 & 2 & \\
\hline Bolivia & 1 & & 2 & \\
\hline Brazil & & & 2 & 1 \\
\hline Columbia & 2 & & & 1 \\
\hline Ecuador & 1 & & & 2 \\
\hline Honduras & 1 & & & 2 \\
\hline \multicolumn{5}{|l|}{ Africa } \\
\hline \multirow{2}{*}{\multicolumn{5}{|c|}{ Central African }} \\
\hline & & 2 & & 1 \\
\hline Djibouti & 1 & 2 & & \\
\hline Gambia & & 2 & & 1 \\
\hline Kenya & & & 2 & 1 \\
\hline Niger & & 2 & & 1 \\
\hline Uganda & & & 2 & 1 \\
\hline \multicolumn{5}{|l|}{ Asia } \\
\hline Bangladesh & 2 & 1 & & \\
\hline India & 2 & 1 & & \\
\hline Indonesia & 1 & 2 & & \\
\hline Malaysia & 2 & & & 1 \\
\hline Pakistan & 2 & 1 & & \\
\hline Thailand & & 2 & & \\
\hline $\begin{array}{l}1=1 \text { st cause } \\
2=2 \text { nd cause } \\
* \text { Some countries }\end{array}$ & include influ & enza and tub & erculosis & \\
\hline
\end{tabular}


Table 1 shows the infectious diseases most frequently notified in some of the countries of the developing world. In Latin America, respiratory tract infections are the most common, followed by malaria and measles. In several African countries, malaria is the disease most frequently notified, with gastrointestinal infections in second place. In Asia, gastrointestinal infections are the most common, with respiratory infections in second place.

On the whole, those diseases confined to tropical areas, except for malaria, play a lesser role in the total morbidity in most of these countries, although in Mexico amoebiasis and in Paraguay ankylostomiasis are the second most common infections notified. However, they are responsible for a great deal of chronic ill health.

The age distribution of victims of these diseases varies with the type of infection, but in all events, as shown in Table 2, gastroenteritis and respiratory diseases are the cause of a significant proportion of deaths in the first year of life. This is in sharp contrast to the situation in developed countries.

Although poor housing and low standards of hygiene are responsible for much of this disease pattern, the most important

TABLE 2 - Comparison of some causes of infant mortality in developed and developing countries (8).

Total population (millions)

Infant deaths, all causes Acute gastroenteritis (\%)

Acute respiratory diseases

\begin{tabular}{|c|c|c|c|}
\hline Thailand & Venezuela & $\frac{\text { West }}{\text { Germany }}$ & USA \\
\hline 44 & 12 & 61 & 216 \\
\hline 29211 & 18391 & 8482 & 46975 \\
\hline $2646 \quad(9)$ & $3435 \quad(19)$ & $69(0.8)$ & 645 (1) \\
\hline $3980 \quad(14)$ & $2232 \quad(12)$ & $414 \quad(5)$ & $1905 \quad(4)$ \\
\hline
\end{tabular}


underlying factor in the impact that infections have on populations is that of malnutrition; and when special conditions such as the failure of the food supply, due to climatic reasons such as drought, or the outbreak of a war disturb an already precarious balance, increased deaths result. The success of populations everywhere has been dependent on an abundant food supply, and where that fails, the population fails: malnourished mothers bear infants who are underweight and prone to severe reactions to what should be trivial infections.

The effects of malnutrition are reflected not only in the infants but also in the adult population. It has been calculated that two million people died in Vietnam in 1945 as a result of famine following floods and typhoid, and in the Karomoja region of Uganda in 1980, 30,000 people died after drought destroyed their crops.

The famines which occur from climatic disasters or war may cause death directly from starvation. But the added impact of infectious diseases, taking a severe course as a result of the fall in resistance, compounds an already serious situation.

As a result of the loss of key workers, either by death or inanition, the soil may not be tilled, crops may not be planted, or harvests may not be gathered. This perpetuates the cycle of malnutrition, even famine, leading to further poor health in the mothers and the births of more underweight infants who succumb easily to intercurrent infection. The escape from this cycle, if aid is not obtained from richer countries, comes when a sufficient depletion of numbers has occurred so that the inadequate food supplies will just suffice to feed those still living, or when the agents of infectious disease die out from the lack of sufficient new hosts in which to spread.

The balance between population and food supply is clearly critical, and it could be that infectious diseases simply take advantage and exploit the failure of man to feed himself adequately. 
In much of the world this balance has been maintained partly by the distribution of food that can be grown from overproducing agricultural countries to those without the land or climate to grow enough for their numbers.

\section{CONSEQUENCES OF POPULATION CHANGES}

Perhaps because of the finality of death, one comes to regard it as a bad thing. Therefore, many deaths, from whatever cause, which result in a reduction in population may be seen as having unfortunate implications for the world.

It has not, however, always been so regarded. It has been argued that high infant mortality and low life expectancy in survivors are necessary to maintain a balance of population with available food supplies and other resources. It has also been argued that there have been per capita gains with depopulation. Those who survived epidemics in rural areas moved to cities, developed skills, and created a culture that would not have materialized had they remained in a rural situation. On the other hand, a fall in population is a misfortune in terms of human suffering and wasteful of human energy, so the hard-won advances of a once thriving population may not be maintained. Perhaps the most important aspect of a high death rate from infectious disease is that it reflects the absence of what might be regarded as basic human rights to have enough to eat, shelter, clothing, and fair health and indicates the failure of man to take advantage of the resources available in the world.

Eradication or control of infectious disease has important results: an improved life span with improved health and energy to make further advances in human development and culture, and the energy available for people to seek new sources of food, to develop new skills, and to flourish. On the other hand, this high survival rate may mean that a population explosion will occur which will lead to a lack of food, water, and other facilities, because the world does not have enough of them. Besides this, a dense population may lead to a desire for 
expansion to seek new territory for development which could possibly only be obtained by taking what belongs to others, that is, to wage wars.

This viewpoint has many supporters and is one of the main reasons put forward for the planned limitation of family size. A contrary view has been proposed by Simon (5) who believes much of the information published suggesting that the resources of the world are finite is incorrect and does not fit with the evidence.

One of his points is that there is not only no long-term negative effect of population growth upon the standard of living, there is in the long run a positive effect of additional people. Therefore, we should not fear an enlarged world population, and if one believes this, it follows that if one does no more than what is already being done, the world population, deprived and unhealthy as it is, will continue to increase.

Whether resources are finite or not, it seems on other grounds that the world population would probably cease to increase at the present rapid rate if efforts were made to improve the duration and quality of life of peoples in most of the world. In this way, with better health and prospects, these populations would probably do what has already been done in the developed world: begin to limit their birth rate to bring about the sort of modest multiplication that would make the resources of the world abundantly available for the foreseeable future.

\section{CONCLUSION}

Until about one hundred years ago, death rates and the general prevalence of disease were roughly the same in all countries. The fall in mortality in Europe has coincided with a rapid expansion of scientific knowledge, including that of infectious disease processes.

Infectious disease in the developing world has, however, not obviously decreased and underlies a great mass of health hazards 
which have their main impact on the young. The infant mortality in these areas runs at a level not very different from that which used to occur in the now developed world. As Farr (1) put it in 1839, writing of the situation in England, "Besides the plagues, the tempests of the atmosphere of life, there is another vast noiseless legion of diseases marching at an even pace, neither exhibiting aggravation nor creating sudden desolation but never halting day and night and less under the control of external circumstances." Curiously enough, it was at this very time that it became apparent that correcting overcrowding, lack of clean water, and sewage disposal might bring about improvement even when the causes of the diseases were unknown. Another observation by Farr was that "hunger destroys a much higher proportion than is indicated in the registers and in every other country; but its effects like the effects of excess, are generally manifested indirectly in the production of diseases of various kinds." Greenhow (3) said much the same thing in 1858: "Diseases of insufficient nourishment form a very considerable part of the cases which contribute to the total of scrofulus ailments - they are in fact starvation disorders." The interesting thing is that populations in those days, despite all the famines and diseases which afflicted them, increased steadily in numbers.

The same pattern is seen today. The more apparently miserable the life and the more the diseases, the greater the number of children are born, and despite the numbers that do not survive for even a year, and despite all the shortness of life for those that survive, the birth rate results in a steady increase in population.

Although there are arguments for and against the uncontrolled increase in numbers, the developed countries have reduced their population increases to such levels that it is now possible that problems will arise from a lack of people to maintain the levels of achievement. 
It is certainly possible to bring about a similar situation in the developing world. Which factors need to be considered first is perhaps not yet determined, but help in the provision of food must be high on the list with improved hygiene, housing, and health care to reduce the still enormous impact of controllable infectious disease.

\section{REFERENCES}

(1) Farr, W. 1839. First Annual Report of the RegistrarGeneral of Births, Deaths and Marriages in England. London: Longman, Orme, Brown, Green and Longmans.

(2) Gottfried, R.S. 1978. Epidemic Disease in Fifteenth Century England. Leicester: Leicester University Press.

(3) Greenhow, E.H. 1858. On the different prevalences of certain diseases in different districts of England and Wales. In Papers Relating to the Sanitary State of the People of England. Report to the General Board of Health. London: H.M.S.O.

(4) Shrewsbury, J.F.D. 1970. A History of Bubonic Plague in the British Isles, pp. 157, 181. Cambridge: Cambridge University Press.

(5) Simon, J.L. 1980. Resources, population and environment: an oversupply of false bad news. Science 80: 1431-1437.

(6) Trevelyan, G. 1942. English Social History, p.8. London: Longmans Green.

(7) World Health Statistics Annual Infectious Disease: Cases 1979. Geneva: WHO.

(8) World Health Statistics Annual 1980 Vital Statistics and Causes of Death. 1979. Geneva: WHO. 